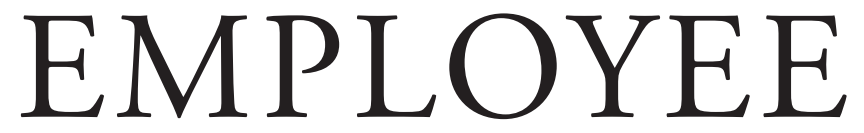

\title{
ENGAGEMENT:
}

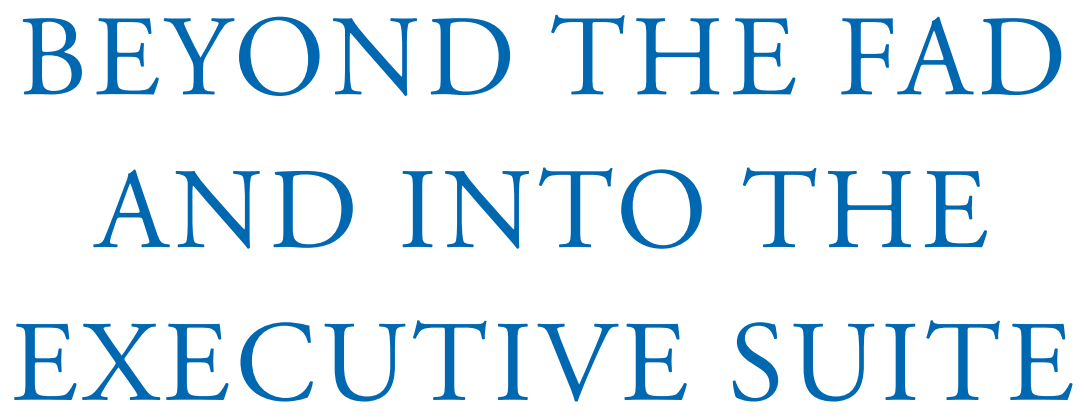

Theresa M. Welbourne

W

hen you hear the word engagement, you might think of long-term commitment, marriage, diamonds, family, and celebration; however, today the word is associated with one of the hottest topics in management. Everyone seems to be on the path to getting their employees engaged. The claim has been made that engagement is needed for higher levels of firm performance, and consultant studies estimate that only 14 percent to 30 percent of employees are engaged at work.

But to date, despite a surge in interest in improving engagement, people still disagree about what employee engagement is, how to go about getting it, and what it looks like when it is achieved. Additionally, with all the attention given to reported levels of low employee engagement, there are few if any statistics on what a realistic level of engagement should be for employees overall and for various subgroups of workers.

In particular, very little attention has been given to the engagement levels of the people running organiza- tions - the leadership and management teams. Regardless of what definition of engagement is used, if it is something organizations are trying to do to employees rather than a quality that leaders are demonstrating through example, the interventions associated with engagement will fail.

In this article, I focus on the context and behaviors of employee engagement. I do this to understand what may be causing the reported low levels of engagement and to spell out the critical role that leaders play in improving performance through employee engagement. To study the framework for engagement, I introduce the role-based model of performance. This model spells out five specific roles that employees occupy at workand the links between these roles and improved firm performance tell the story of what happens when employees become engaged at work.

Knowing the relationship between employee behavior and firm performance, while simultaneously understanding the context in which leaders are running their 
organizations, it becomes clear that engagement is not going to be a quick fix. Leaders face challenges of being engaged themselves, getting structural barriers out of the way of engagement, and dealing with an employee contract that does not support engagement at work.

\section{Origins of Employee Engagement}

Employee engagement has appeared on the management scene in a big way fairly recently. A review of recent history helps to clarify why it is so popular today. Prior to the 1980s, employers expected loyalty to the organization, and in exchange for that commitment, they offered lifetime employment. Then in the 1980s organizations started to change that contract.

With increased global competition, employers needed to be more flexible in their deployment of employees. Plants were closed and then reopened in countries where wages were lower, and as business became global, leaders needed more control over wage and benefit costs to compete effectively. Employees learned the hard way (through layoffs) that loyalty was no longer rewarded. College seniors were told they could no longer expect long-term employment, and career progress became viewed as a spiral instead of a ladder. The rules of the game changed, and leaders in business initiated the evolution.

The workforce has changed. Employers wanted it to change; however, in many cases, they did not quite want everyone to change. The new employment contract backfired. High-quality talent left organizations, and productivity suffered. Skilled employees were not willing to put in overtime and extra effort, and employers started to see increases in productivity slow down. This situation created the need for something new, and at least one of the initiatives was employee engagement.

The driving need today is for business to continue to improve productivity in a global environment where continuous change is making it difficult to compete. This desire to do more is combined with the mandate to do so with less, and one of the only outlets left for making this happen is employees. However, given the

\section{Employees learned the}

hard way that loyalty was

no longer rewarded.

employee contract as it has been redefined, it is not easy for employers to snap their fingers and simply get employees to do more. Thus, the employee engagement movement arrived as a way to solve this problem. The experts claim that engaged employees do more; therefore, to get more out of less, the logic would be that managers simply need to engage their people.

\section{Behavior, Not Attitudes}

Many case studies detail how efforts to improve employee engagement can improve firm performance outcomes (such as sales and profitability) and other outcomes such as absenteeism, customer service scores, and more. However, these data are primarily focused on employee attitudes (that is, the degree to which employees describe themselves as motivated, inspired, feeling liked by coworkers, having opportunities to excel, and so on), and they do not spell out the process by which these employee attitudes lead to changed behaviors or what specific actions drive performance. In today's environment, where the employee contract has evolved considerably, the process by which we expect engagement to happen needs to be fully understood so that managers can change contract terms or other context issues to enable full employee engagement.

The only way to improve employee engagement across multiple organizations is to know what it looks like; the behaviors (not just attitudes) must be specified. Behaviors, to date, are the missing link in employee engagement. Thus, to fill that void, I suggest a role-based 
performance model as an option for providing a definition of the behaviors of employee engagement.

\section{Role-Based Performance}

The role-based performance model helps explain employee engagement by starting with the end goal in mind. The objective of all employee engagement initiatives is improved firm performance. The role-based performance model (see Figure 1) helps identify the types of behaviors needed from employees to drive performance. The model defines five key roles that employees occupy at work:

- Core job-holder role (what's in the job description)

- Entrepreneur or innovator role (improving process, coming up with new ideas, participating in others' innovations)

- Team member role (participating in teams, working with others in different jobs)

- Career role (learning, engaging in activities to improve personal skills and knowledge)

- Organizational member role (citizenship role or doing things that are good for the company)

I developed the role-based model for a large research project I conducted that focused on the determinants of long-term firm performance. The study was based on theories and prior work on what employers need from employees and what they reward. The model was

\section{Firms win in the market}

\section{when they develop human}

resources in a way that is

not easily replicated.

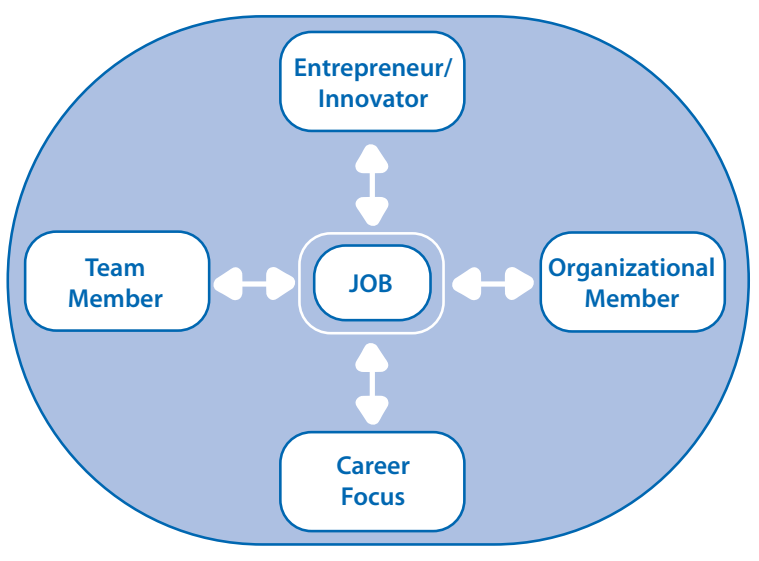

FIGURE 1. ROLE-BASED PERFORMANCE MODEL

validated with results obtained from numerous withinfirm studies. The core ideas behind use of the model are that firms win in the market when they develop human resources in a way that is not easily replicated by their competition.

The roles that are not easily copied are the non-core job roles. When employees put in enough time within an organization to understand how to innovate (not just new products, but processes), they add value that an employee newly off the street cannot contribute. When employees are part of a team and all team members develop company-specific knowledge, that asset is something that cannot be easily copied by a competitor. As employees move from job to job within the organization and they build their own company-specific career knowledge, or as they teach others within the firm, the advantages of this firm-specific, career-based action cannot be easily imitated by another organization. When employees understand the inner workings of the organization, and they begin to engage in behaviors that support the company overall (instead of just their own job), this type of activity is not easily replicated by another organization, and these behaviors bring high value.

However, on the opposite side of the spectrum, if a company values only the core job role, and employees engage in behaviors exclusively associated with the core job, these jobs are very easy for competitors to copy. It is a simple matter to replicate this type of company, hire employees 


\section{Improving employee}

engagement calls for

specifying the behaviors

(not just the attitudes).

in another region or country who can be paid less money, and then compete with the original employer.

The net is that the core job role is important, but it alone will not result in long-term competitive advantage. This notion is consistent with what we are hearing in the employee engagement articles and books. Writers and experts talk about "above and beyond" behaviors, and they discuss discretionary effort, but these outcomes are rarely specifically defined or measured. Using the role-based model one can describe what it looks like to be engaged at work.

Employee engagement improves when employees are successful working in both the core job and the non-core job roles.

The result of employees' engaging in the non-core job roles will be new ideas, improved process, enhanced product lines, more skilled employees, higher service levels, career movement within the organization, employees' going above and beyond to help the company even when a project is not officially part of the immediate job, employees' working on teams to create new synergy that was not there in the past, employees' caring about the outcomes of projects because they know that the organization values their going beyond their core job, and more. The result of spending time and doing the noncore job roles well is company-specific assets that cannot be easily copied. These assets, then, drive long-term competitive advantage and firm performance.

\section{Leader Energy and Engagement}

To provide the environment where employees can be successful in both the core job and the non-core job roles, a few things are necessary:

- Leaders themselves have to be engaged; they need to work and succeed in both their core job and non-core job roles.

- Leaders need to clearly articulate how each role helps support the business strategy and plan.

- Leaders have to create an environment where the non-core job roles are valued, and they must remove barriers to employees' working in the noncore job roles.

These three conditions for engagement are not easy for leaders to meet. The work environment in most organizations is becoming more stressful, with employees not being able to do their core jobs in 60-hour work weeks, and leaders themselves are becoming burned out, confused, and disengaged. This is not a ripe environment for engaging employees or leaders.

Data on the context of engagement come from a study that I have been conducting over the last three years. The research is designed to examine leadership through an ongoing dialogue and data-collection process with leaders from multiple organizations. The study involves short pulse surveys sent every two months to more than 4,000 executives.

When leaders and managers are feeling distracted and overworked, their employees are doing much worse. 
A subset of these data-collection efforts includes a measure of personal energy (or sense of urgency) at work, and the measurement process includes an open-ended comment question that asks respondents to explain the factors affecting their energy. The study focuses on energy because my prior research found it to be an important determinant of both individual and firm performance in several large-scale studies involving thousands of organizations and then in multiple case studies conducted since 1996.

The leadership pulse results show that, overall, leaders are reporting personal energy levels at work to be lower than where they say they are most productive. To understand this data, I asked respondents to explain their energy scores and why they are suboptimal. Below are some sample quotes from the data:

"Unclear and conflicting signals."

"Lack of information."

"Personnel problems."

"Non-recognition of extra effort-nobody appreciates."

"Stress, overwork, constantly changing priorities."

"Continuous crisis management and cost cutting moved energy level to both extremes."

"Too many projects; lack of completion."

"The feeling of overloading in the workplace."

"Today's pace is too fast, at home and at work, and it is difficult to stay ahead of the game."

In this study I obtained more than 250 single-spaced pages of comments that indicate that many senior executives are tired, struggling to keep pace with their workloads, unclear about their own priorities, not confident in their own business strategies, and overall not doing well. This leadership research is only the tip of the iceberg. When leaders and managers are feeling confused, distracted, and overworked, their employees are doing much worse. I have been collecting energy data from employees throughout the world since 1996. The research shows that a decline in leader energy predicts reduced employee energy scores.

\section{Non-core job roles}

are what generate

company-specific assets.

For example, here are sample quotes from a group of employees reporting to a manager whose own energy levels are suboptimal, low, and declining:

"Workload is not evenly distributed."

"Too much work and not enough time to get it done."

"The pace of my work is too much."

"I don't know how to spend my time; I have too much to do."

"I need help."

"There are not enough resources to get the job done."

"Many of us are just burned out."

"We have no idea what the strategy is or where we are going."

"There are not enough communications."

\section{The Leader and Employee Engagement Challenge}

This research suggests that many leaders are creating or are in an environment where employee engagement will be very difficult to achieve. When leaders are working at an energy level that is suboptimal, and when they have a difficult time merely getting their own jobs done, they will not value nor be interested in anyone engaging in the non-core job roles.

The type of environment leaders are discussing in the leadership pulse project is not conducive to high levels of employee or leader engagement. This is why having 
a concrete definition of what engagement looks like is so important for leaders. The organization must provide a context where people who move to the engaged state are rewarded or at least not punished for what they are doing. In a company where everyone is reporting being overworked, employees and managers will not tolerate time spent in the non-core job role even if a logical argument can be made for how that effort will benefit the organization in the long run.

In sum, the leadership pulse data reports a large proportion of leaders are not optimally energized at work, and the cause seems to be related to workload and a heavy focus on the core job role. At the same time, employees do not expect their employers to be loyal to them; they do not anticipate nor want jobs for life, and they are willing to leave their company when a new opportunity arises. In this highly complex environment, we need to ask some hard questions:

- Should anyone be surprised that only a small majority of employees are reporting being "engaged"? The employee contract was changed in ways that mean employers should have anticipated disengagement.

- Can anyone realistically expect to raise "engagement" when there are no associated rewards?

- Should we expect to improve engagement (if we define it as doing the non-core job roles) if employees are working for leaders who are having problems energizing themselves at work?

- Can employees or leaders afford to take time away from the job role when there are so many pressures on merely getting the job done?

\section{A systematic approach to} employee engagement begins with the leadership team.

\section{The millions of dollars}

being spent on employee

engagement programs may

be wasted money.

- If the leadership team has no time to engage in anything other than the core job role, why would they value non-core job role-based behavior from their own employees?

Putting the pieces together, one could speculate that the millions of dollars being spent on employee engagement programs may be wasted money when the context for engagement does not exist. To change firm performance through people, a significant effort must begin with the leadership team. The leadership team must be engaged themselves; they need to know what it looks like to engage people at work, and they must be role models for this behavior with their direct reports-who then do the same for their employees.

\section{Suggestions for Success}

Improving conditions for employees and leaders at work so that they can engage in both core job and non-core job roles is an important goal for firms that want to gain competitive advantage. The role-based model is a way to start systematically addressing the problem of performance and the proposed solution of engagement.

If we define "engaged" employees as those who work and succeed in the non-core job roles, then a systematic approach to employee engagement would not start with an all-employee attitude survey (as has been done in many engagement programs). Instead, it 
would begin with the leadership team. Here are some suggested actions leaders can take to ensure that the people in charge of engagement are engaged themselves and that their organization has an environment that can support employees' contributing to productivity in a way that is defined by the role-based model:

- Conduct a business analysis to determine what roles are really valued in their organization and what roles are needed to achieve business plan objectives. This analysis should lead to identification of any gap in shared understanding of how employees should be allocating time and effort and what is rewarded in the organization.

- If the non-core job roles are not valued (by the managers who interact with employees daily), analyze the types of structural and strategic changes required to align the organization so it can compete effectively.

- Determine what leadership education is necessary to create a culture where both core job and noncore job roles are valued and rewarded.

- Examine in detail what structural impediments may exist to spending time in the non-core roles. These can be formal processes such as performance management systems that only focus on the job, or they can be informal norms.

- Assess the ways in which the various roles need to be enacted throughout the year. The importance of roles may change based on seasonality of the industry or work demands; they also may be different for various occupations. This type of detailed understanding is needed to assure continuous alignment.

- Engage employees in the right roles at the right time. Conduct assessments to understand the determinants of engagement in the various roles as opposed to engagement overall. Using this data, you can develop interventions to help retain employees who are interested in engaging in both the core job and non-core job roles.

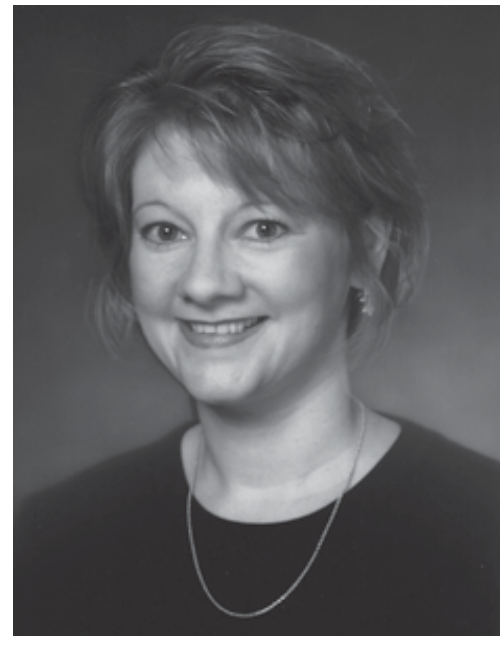

Theresa $M$. Welbourne is the founder, president, and CEO of eePulse, Inc., a technology and leadership research organization, as well as an adjunct professor of executive education at the Ross School of Business at the University of Michigan. She has more than 25 years' experience conducting research, teaching, consulting, and writing on the topic of leadership in high-growth and highchange organizations. She is also the editor-inchief of Human Resource Management. Visit www.eepulse.com.

Organizations need more engagement at work. They need leaders, managers, supervisors, and employees who will take time to go above their core job roles if the business is to remain competitive in the global economy. However, employers cannot expect a magic formula to make engagement happen. It will be a long journey that starts at the top of the organization and moves its way throughout the business. 